\title{
REDESENHANDO A BORRACHALIOTECA: DESIGN SOCIAL
}

Clara Santana Lins Cerqueira

Universidade do Estado de Minas Gerais

clara.slc.12@gmail.com

Rita Ribeiro

Universidade do Estado de Minas Gerais

rribeiroed@gmail.com

Resumo: Este artigo tem como foco apresentar o conceito de design social perpassando em exemplos de como o design pode ter sentido ativo na melhoria de vida das pessoas. Compreender o que são bibliotecas comunitárias e a importância destas para a comunidade bem como exemplos que demonstram tal importância para o senso comum. Investigar a Borrachalioteca, biblioteca comunitária da cidade de Sabará, em Minas Gerais, que é o foco desta pesquisa aplicando o conceito de design social para este espaço e desenvolver soluções para suas necessidades.

Palavras-chave: design social, cultura social, bibliotecas comunitárias.

\begin{abstract}
This article focuses on the presentation the concept of social design permeating into examples of how design can have active sense in improving people's lives. Understand what community libraries and their importance to thecommunity as well as examples that demonstrate this importance for common sense. Investigate the Borrachalioteca, community library in the city of Sabará, which is the focus of this research applying the concept of social design for this space and develop the best solution for the needs of the same.
\end{abstract}

Keywords: social design, social culture, community libraries. 


\title{
1. INTRODUÇÃO
}

A cultura é de um modo mais subjetivo, aquilo que acolhe um indivíduo, que o faça sentir-se vivo e aceito. É o fazer existir. Compartilhar com outros indivíduos as mesmas ideias e opiniões é uma nova identidade que toma forma. Um novo pensar com pessoas que se identificam, demonstrando nesse círculo, um processo de formação cultural.

\begin{abstract}
O homem é o resultado do meio cultural em que foi socializado. Ele é um herdeiro de um longo processo acumulativo, que reflete o conhecimento e a experiência adquiridos pelas numerosas gerações que o antecederam. A manipulação adequada e criativa desse patrimônio cultural permite as inovações e as invenções. Estas não são, pois, o produto da ação isolada de um gênio, mas o resultado do esforço de toda uma comunidade. (LARAIA, 2013, p.45)
\end{abstract}

A relevância desse trabalho reside na importância de resgatar os valores do espaço físico de leitura, ou seja, os vínculos afetivos e trocas socioculturais promovidas pela interação entre os usuários e o espaço. Dessa forma, o Design configura-se como estratégico para tangibilizar nos espaços a interação e relação do usuário, resgatando a identidade da comunidade local, compreendendo as suas necessidades e solucionando-as da melhor forma a demanda proposta.

A metodologia utilizada na pesquisa foram questionários via internet, pesquisa bibliográfica e levantamento do espaço e materiais, avaliação do projeto, redação de artigos e relatório final: avaliação da usabilidade dos materiais projetos e redação de artigos apresentando o desenvolvimento do projeto.

\section{O DESIGN SOCIAL}

O design tem como seu principal papel interpretar as relações socioculturais, seus símbolos e seu contexto transformando sentimentos em experiências, objetos, espaços e interação social.

O design social é comumente confundido com aquele que somente atende a faixas periféricas da sociedade, com algum trabalho do tipo voluntário. Entretanto, o design social abrange todos os aspectos que formam uma sociedade, como a cultura, a economia, a política, a cidade - como um órgão vivo e sistemático -, os símbolos que nela estão inseridos (abstratos ou concretos), a religião, e etc. O foco do design social é portanto o ser humano e suas relações compreendendo todos esses aspectos que formam a sociedade. São preocupações deste tipo, relacionadas com a qualidade de vida dessas pessoas, que movem o Design Social, uma área do design que cada vez mais cresce no mundo.

“O Design Social apoia-se no entendimento de que nós designers, somos os
responsáveis por criar pontes, facilitar a relação entre o indivíduo e o
mundo que o cerca e deixando de lado qualquer discurso inocente, fica
evidente o tamanho da nossa responsabilidade na construção e
desenvolvimento da sociedade a nossa volta. É preciso deixar claro, no
entanto, que o Design Social nada tem a ver com assistencialismo, as ações
desta vertente do design têm como foco, transformar situações de
desigualdade social e tecnológica, oferecendo através do design, recursos
para que estas barreiras sejam superadas, gerando oportunidades de 
desenvolvimento com resgate da cidadania e a dignidade." (Klaiber Miranda do Design Coletivo)

A cidade representa uma estrutura, que é consolidada a partir de construções simbólicas e culturais. Os indivíduos que nela habitam interagem com os seus espaços de várias formas. O que irá definir as formas de uma cidade no seu aspecto global como na arquitetura e a cultura social, serão os grupos sociais que nela se dividem.

A cultura, a economia, a ética e a comunicação, a estética e funcionalidade tornam o design interdisciplinar, multifacetado e flexível, conversando com as distintas necessidades das sociedades. $O$ design se propõe a criar soluções que possam atender a várias pessoas, com o intuito de ser inclusivo e flexível. Soluções estas que são geralmente caracterizadas pelo pragmatismo e democráticas.

Todos os homens são designers. Tudo o que fazemos quase todo o tempo é design. O design é básico em todas as atividades humanas. Planejar e programar qualquer ato, visando a um fim específico, desejado e previsto, isto constitui um processo de design [...] design é compor um poema épico, executar um mural, pintar uma obra de arte, escrever um concerto. Mas design também é limpar e organizar uma escrivaninha, arrancar um dente quebrado, fazer uma torta de maçã, escolher os lados de um campo de futebol e educar uma criança (PAPANEK, 1995 apud NOGUEIRA, S.D., p. 6).

Pesquisas, planejamento e testes fazem parte de um projeto com soluções eficazes e que se adequem a população. Uma solução de design apenas fará sentido se o usuário se reconhecer no objeto ou no espaço, do contrário esta não fará sentido de completude no indivíduo.

\subsection{A função do design na melhoria de vida das pessoas}

$O$ design tem como função pensar nas necessidades do ser humano e promover melhoria na qualidade de vida. Um exemplo atual disso é como esses profissionais têm projetado, pensando como demanda universal, a sustentabilidade.

O design social é abrangente e múltiplo, porque se compreende como sua maior demanda atingir o coletivo, respeitando os valores simbólicos, materiais e imateriais e socioculturais de cada comunidade. Sua função está ligada a atender necessidades reais e atuais do ser humano, trazendo assim, capital e soluções rentáveis, através de artigos e produtos de consumo, associadas à sustentabilidade.

Compreende-se que o design social engloba o senso de alteridade e é receptiva a qualquer que seja sua demanda passando assim a projetar com um único objetivo, trazer melhoria na vida da comunidade. Desta forma, promove-se inovação sociocultural, criatividade, evolução tecnológica entre outros fatores que englobam o crescimento social.

Portanto, desenvolver um projeto que trabalhe a valorização da cultura local precisa, além de reunir referenciais locais e aplicá-los em produtos para posterior comercialização, promover diálogo com os agentes locais para que o resgate seja eficiente e coerente com a realidade. Esse diálogo entre os agentes locais e a comunidade vai ao encontro da prática educativa emancipadora proposta por Paulo Freire, centrada nos sujeitos, os quais são produtores de conhecimento e não apenas receptores. O diálogo, então, 
configura-se como o método de relação entre os sujeitos, às diversas partes se encontram em permanente interação. (FREIRE apud MELLO at al, 2006)

Nota-se que o design não é apenas sinônimo de produtos e consumo somam-se a ele valores. Valores estes que podem ser manipulados pelos meios midiáticos e adquiridos pela sociedade, mudando, assim, todo um paradigma social e cultural. 0 design torna possível a materialização cultural, consequentemente possibilitando a expressão identitária de uma comunidade.

\subsection{Design social - definições}

De acordo com Löbach (2001), o design social observa questão socioculturais direcionada na observação pelos problemas da sociedade e tendo como objetivo a melhoria das condições de vida de comunidades, colocando os problemas do usuário em foco, respeitando o meio ambiente, a cultura como valor agregado e privilegiando a mão de obra local. Victor Papanek, em 1972 no seu livro intitulado "Design for the real world", aponta para o potencial danoso do desenho industrial (PAPANEK, 2004) motivando vários designers a pensar na causa e consequentemente estes se envolvem cada vez mais com assuntos que são demandas diárias pelo mundo todo, como questões sociais, resolvendo problemas em comunidades carentes, pensando também em produtos sustentáveis e visando a diminuição de impactos nas futuras gerações.

Trata-se, dessa forma, de uma relação simbiótica entre os profissionais e a comunidade. $O$ designer precisa estar inserido no contexto e observar a comunidade. A comunidade precisa mostrar as suas necessidades, sejam elas diárias, de primeira instância ou mesmo necessidades secundárias. Uma função complementa a outra tornando a interação e o resultado do trabalho possível.

\subsection{Exemplos de design social}

O design social tange a possiblidade de a comunidade local, de fato, usar o produto ou serviço proposto que auxilie nas atividades diárias. A maior ferramenta do designer, geralmente, é com materiais disponíveis no local, contudo há vários exemplos de alta tecnologia que são inseridos na comunidade com o mesmo intuito. Outro ponto é que as soluções, em sua maioria, são caracterizadas por baixo custo e fácil manuseio para tornar possível a usabilidade pelos usuários.

1. Eliodoméstico, da designer Gabriele Diamanti, é um projeto open-sourced que transforma água salgada em água doce e foi projetado para pessoas em países em desenvolvimento. Necessitando apenas do Sol, produz até 5 litros/dia.

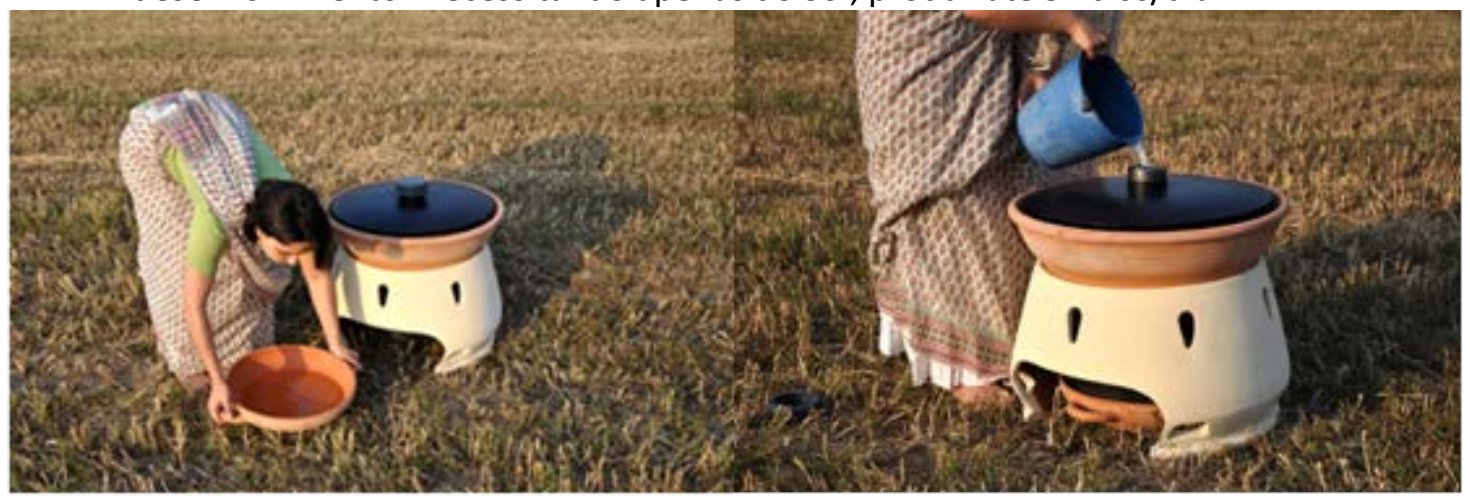

Figura 1: Eliodoméstico.

Fonte: http://designechimarrao.com.br 
2. O Hippo Roller foi concebido em 1991 com o intuito de proporcionar praticidade à populações carentes na África. É usado em mais de 20 países africanos e contabiliza uma ajuda a aproximadamente 300.000 (hipporoller.org/social-impact) pessoas. Muitas delas sofriam de problemas na coluna e no pescoço causados por carregar galões de água sobre a cabeça, por longos percursos. Apesar da simplicidade do projeto (o barril, a tampa e a alça), este beneficia diretamente as populações que não tem acesso à água potável. O produto ainda facilita a retirada de água do barril e a boa assepsia evitando maiores contaminações.
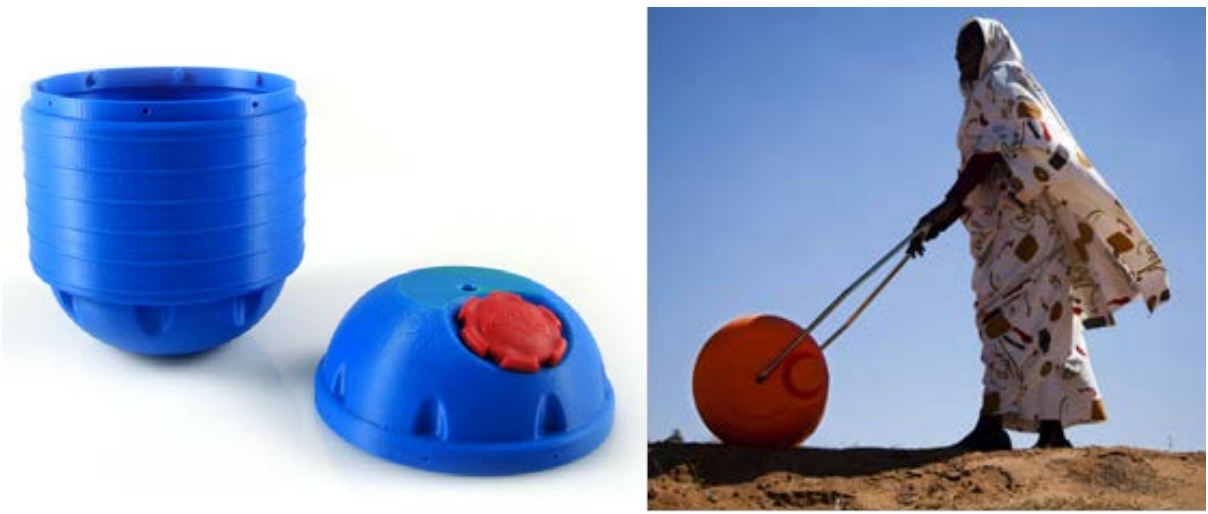

Figura 2: Hippo Roller.

Fonte: http://designechimarrao.com.br.

3. O AdaptAir foi criado por estudantes de Stanforde ajuda crianças com problemas respiratórios a respirar melhor propiciando uma pressão de ar positiva e consistente. O problema que tinha sido identificado nas máscaras nasais usadas não se adaptava aos diferentes tamanhos de faces das crianças, comprometendo o tratamento e, muitas vezes, a vida de crianças com problemas respiratórios graves. O redesenho das máscaras foi pelo Alejandro Palandjoglou. Um exemplo de como o Design - e não só as profissões da saúde - pode salvar vidas.

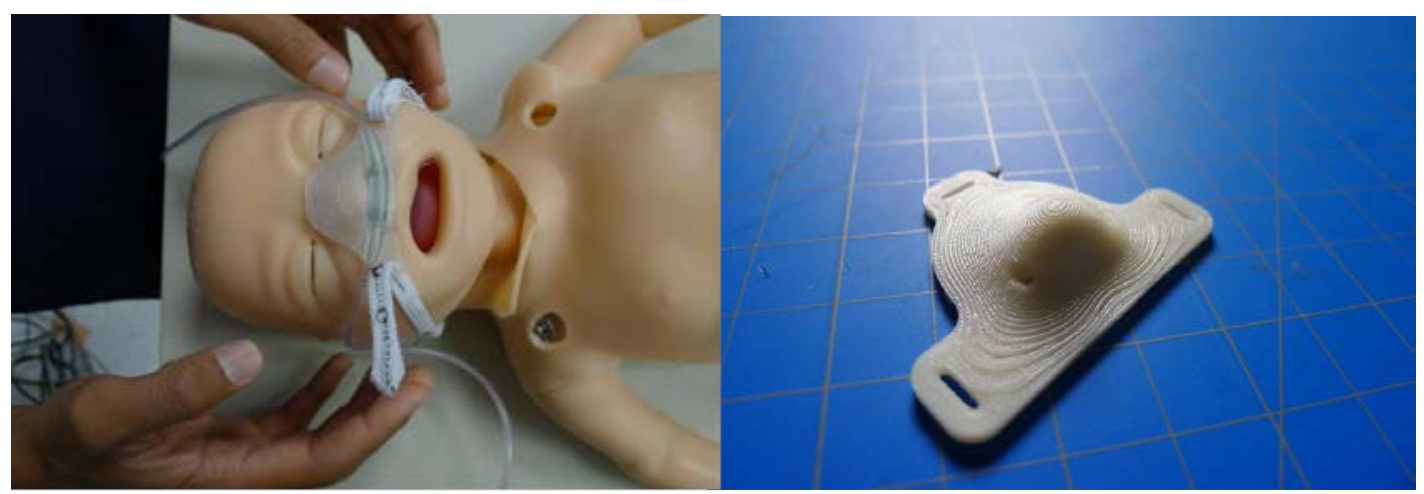

Figura 3: AdaptAir.

Fonte: http://designechimarrao.com.br

A partir dos exemplos pode-se constatar que o design compreende o problema e as necessidades que surgem resultando em soluções que promovem o bem estar social, melhoria de vida e até mesmo salvar vidas. 
Em cada projeto devemos questionar em primeiro lugar a importância que ele terá para a sociedade, se o resultado do processo de planejamento e de configuração é sensato, se há aspectos negativos a considerar. Não deverão ser consideradas somente as vantagens econômicas e sim os possíveis efeitos sobre a comunidade. (LÖBACH, 2001, p. 21).

O design insere também na formação de aspectos socioculturais que podem mudar toda a rotina de uma comunidade. Dessa forma, as soluções são estudadas para minimizar impactos negativos visando sempre o bem estar social da mesma.

\section{BIBLIOTECAS COMUNITÁRIAS}

\subsection{O conceito de biblioteca para a comunidade}

A biblioteca comunitária recebe essa tipologia pelo simples fato de ser criada pela comunidade, gerida pela mesma e sustentada pelos próprios esforços das pessoas que frequentam e se identificam com o espaço. Ou seja, é comum que essas bibliotecas não sejam financiadas pelo governo, desta forma elas existem independentemente do querer do governo o que difere muito das bibliotecas públicas. Estas dependem do dinheiro público subsidiado pelo município ou estado para continuar funcionando através dos funcionários públicos que nela trabalham.

A biblioteca comunitária está destinada a atender à comunidade em geral, e seu acervo geralmente é composto por uma grande variedade de assuntos. Na maioria das vezes, sua gestão é administrada por integrantes da própria comunidade. Criar uma biblioteca comunitária é uma possibilidade de valorização da comunidade local, na medida em que os conhecimentos podem ser levados a um número maior de pessoas já que ela pode se apresentar em vários outros pontos da cidade. Iniciativas como esta mostram o interesse da população por espaços que proporcionem aprendizado, cultura e valorização social. Demonstra também certo grau de nível organizacional, amadurecimento e cidadania por parte da comunidade local, já que assim os próprios usuários se tornam responsáveis pelo processo espaço e consequentemente pelo crescimento cultural, coletivo e individual.

\subsection{Exemplos de bibliotecas para zonas de pobreza}

Cada dia mais as comunidades reconhecem a verdadeira importância de se obter informação e conhecimento. Por isso o número de bibliotecas comunitárias vem crescendo muito entre muitas comunidades no Brasil.

O projeto Bibliotecas Comunitárias "Ler É Preciso" faz parte da ONG Instituto Ecofuturo, mantida pela empresa Suzano Papel e Celulose e Suzano Petroquímica e criada com o objetivo de apoiar a formação de cidadãos críticos, capazes de interagir positivamente entre si e com o ambiente em que vivem.

Atualmente o projeto conta com 80 bibliotecas espalhadas pelo país. A ideia surgiu em 1999 visando o resgate sociocultural da comunidade pois foi detectado nessa época um êxodo considerável de jovens do local, pela falta de atividades e até mesmo de uma biblioteca local. Dessa forma a ONG conseguiu com que o projeto das bibliotecas fosse implantado e hoje auxilia jovens e crianças no que se diz respeito a práticas socioculturais e acesso a informação, voltados para uma consciência de sustentabilidade e ética. 
Acreditamos que é a partir da integração do homem com a natureza, do entendimento de sua relação com o todo, que intenção se transforma em ação, em atitude, para mudar o presente e o futuro para melhor! Está nas ações locais, no pedaço de chão de cada um, a chave para a sustentabilidade e o cuidado com todas as vidas. (ecofuturo.org.br)

Dessa forma, o projeto promove o convite à leitura e a busca para o conhecimento para formar mais cidadãos conscientes, instigando a criatividade, a sustentabilidade, ao respeito sociocultural e preservando a vida. O projeto tem como seu principal argumento que é apenas através da educação que o individuo conseguirá alcançar seus objetivos de maneira integra e preservada para todos.

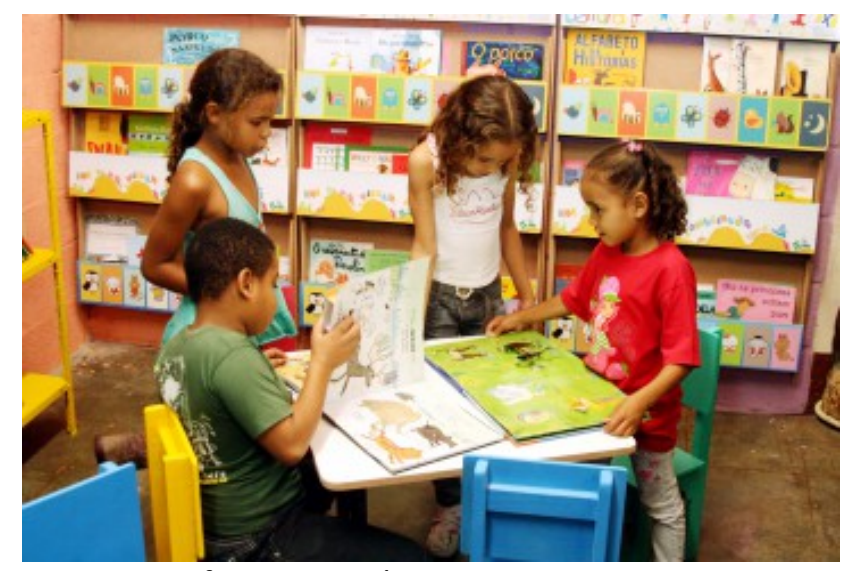

Figura 4: Ecofuturo - Ler é Preciso.

Fonte: http://blog.ecofuturo.org.br/categoria/promocao-de-leitura.

No Alto José Bonifácio, na Zona Norte do Recife com população de aproximadamente 18 mil habitantes, é onde se situa a biblioteca comunitária Amigos da Leitura, que começou em 15 de dezembro de 2004, com uma parceria entre o educador social Fábio Rogério Rodrigues, técnicos do Porto Digital, representantes da Associação Profissional de Bibliotecários de Pernambuco e o Sindicato dos Trabalhadores da Construção Civil. O trabalho na biblioteca é voltado para atividades culturais e educativas, além da oferta de informações de interesse social, como um banco de empregos e cursos articulados com o Senai e o Sindicato dos Trabalhadores da Construção Civil.

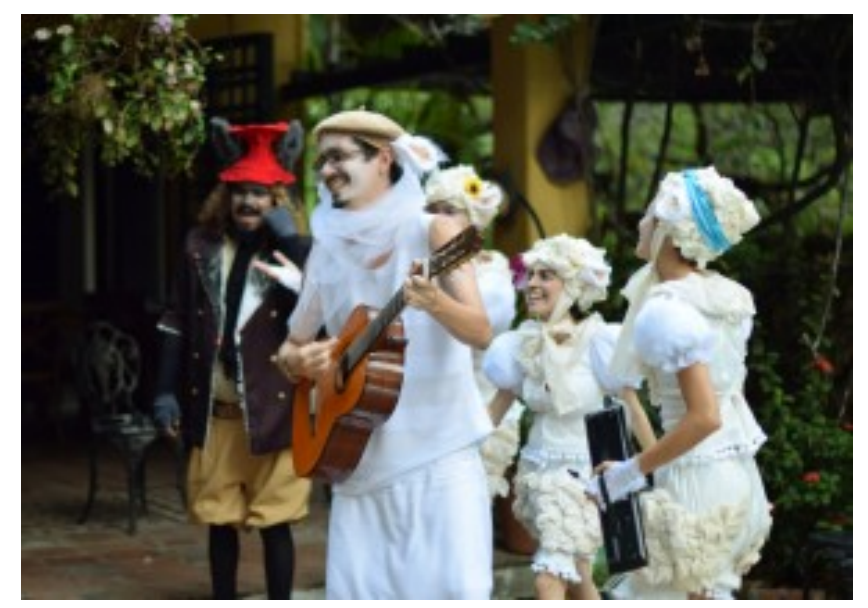

Figura 5: Biblioteca comunitária Amigos da Leitura.

Fonte: http://www.bibliotecaamigosdaleitura.com.br/. 
Neste projeto é também enfatizado o conceito de sustentabilidade agregado ao respeito sociocultural e $\mathrm{o}$ incentivo a leitura. $O$ projeto é viabilizado através de parceiros como o Centro Luiz Freire, Instituto C\&A, Releitura (Rede de Bibliotecas Comunitárias) e Canal Futura. E como patrocinadores contam com o apoio da FUNCULTURA, FUNDARPE, Secretaria de Cultura e Governo do Estado de Pernambuco.

\section{O DESIGN NO REDESENHO DE UMA BIBLIOTECA COMUNITÁRIA}

\subsection{A Borrachalioteca em Sabará}

O projeto da Borrachalioteca começou sem maiores pretensões há 13 anos, na cidade de Sabará, no bairro Caieira, distando a aproximadamente $15 \mathrm{~km}$ da capital mineira, por Marco Túlio Damascena. Do lado da borracharia do seu pai, o espaço foi aos poucos tomando forma, e dessa união se deu a origem do nome - borracharia com biblioteca.

No pequeno espaço que ele tinha, começou a juntar livros e deixar disponível para quem quisesse ler. Muitos livros vieram como doações dos clientes da borracharia do pai e a divulgação do espaço aconteceu naturalmente entre a vizinhança e a comunidade local.

Desde o seu surgimento a intenção do criador era formar mais leitores e proporcionar acesso aos livros de uma forma descontraída e despretensiosa. A consequência disso foi positiva. Os usuários da Borrachalioteca entram tímidos, mas após 5 minutos, estão à vontade, escolhendo livros, sentando em algum cantinho confortável para prosseguir com a sua leitura. Segundo Marco Túlio o segredo sempre foi deixar as pessoas se identificarem com os livros e não impor nenhuma regra como nos "Direitos do leitor", cita ele.

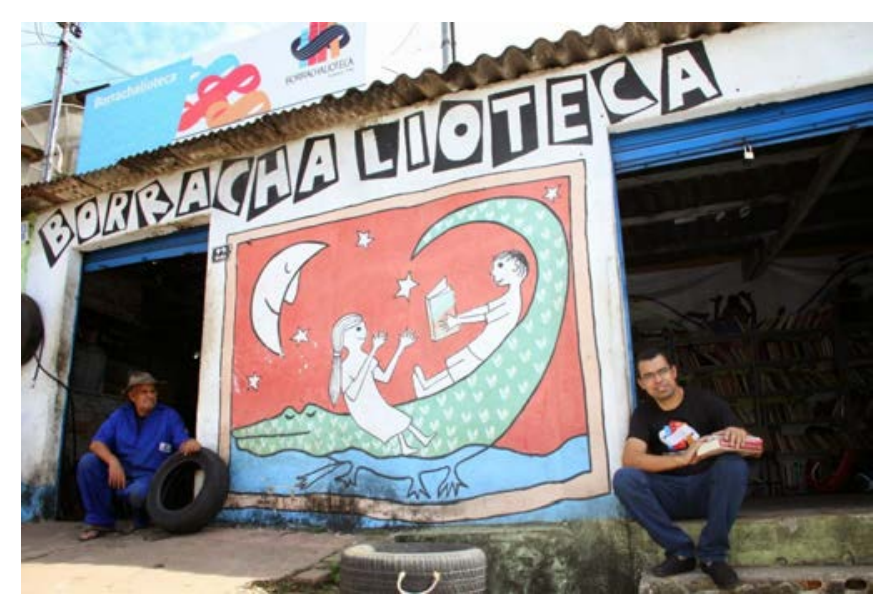

Figura 6: Borrachalioteca em Sabará. Fonte: http://borrachalioteca.blogspot.com.br/

A repercussão aos poucos foi tomando forma. Em 2004, a imprensa televisiva e escrita divulga a Borrachalioteca. Em 22 de outubro de 2004, o espaço toma a cena no Jornal Nacional e sai em uma manchete no mesmo dia no jornal Estado de Minas. Com isso, a demanda e número de usuários aumentam constantemente fazendo com que Marco Túlio repensasse o espaço para continuar proporcionando lazer e conforto para os seus visitantes. Em 2007 foi alugado o espaço ao lado da borracharia do pai No mesmo ano concorreram ao prêmio "Viva a Leitura", em Brasília, ganhando em segundo lugar como o melhor projeto de incentivo a leitura no Brasil. 
A cada ano que passava as doações cresciam mais e mais e dessa forma a necessidade de conseguir outros espaços para realocar estes livros fez-se necessária. Entre 2008 e 2010 foram abertas, a Sala Son Salvador, no bairro Cabral, A Casa das Artes, com livros infanto-juvenis e literatura de cordel, e no Presídio Municipal de Sabará o projeto Espaço Libertação pela Leitura. Em 2013 a Borrachalioteca entra no programa Prazer em Ler - Polos de Leitura - do Instituto C\&A, com a participação de quatro bibliotecas comunitárias de Belo Horizonte. $O$ grupo e agentes culturais têm por objetivo repensar e desenvolver projetos e ações para o incentivo à leitura.

Esse ano a proposta é abrir vários cursos de envolvimento com a comunidade e fora dela. Cursos de palhaço, de teatro com dança, canto e recitar poemas. A Borrachalioteca participa com os Arautos da Poesia, grupo de jovens frequentadores do espaço, que fazem apresentações recitando poemas em várias cidades de Minas Gerais, com o objetivo de levar a leitura e o encanto de se recitar poesias e prosas. $\mathrm{O}$ grupo faz vários ensaios aos fins de semana, com treino para relaxar o corpo e a treinar a entonação da voz. As aulas são ministradas pela esposa de Marco Túlio, Águida Alves de Oliveira, que é professora e criadora dos Arautos da Poesia. O grupo tem aproximadamente 13 jovens entre 6 a 19 anos, que se mostram à vontade com o projeto e participam com muita descontração e prazer.

Hoje com cerca de 12 mil livros no acervo a Borrachalioteca irá comemorar seus 13 anos fazendo uma grande festa no centro da cidade de Sabará. No dia 15 de agosto, será realizado o evento "Trilhas da Leitura" com livros fazendo trilhas pela praça Melo Viana, com a disponibilidade 3 a 4 mil livros. Dessa forma os moradores poderão levar para casa os livros que estiverem nas trilhas e confraternizar com a ideia do incentivo à leitura. Ocorrerão também oficinas de teatro, cordel, sarau de poesia entre outras formas de arte com o objetivo de entreter os cidadãos da cidade e convidar a todos a momentos de arte e lazer.

\subsection{0 projeto Redesenhando a Borrachalioteca}

O projeto se iniciou com o objetivo de ajudar as camadas mais populares da sociedade e entender como o design poderia se inserir para dar apoio social a elas.

A Borrachalioteca, nosso objeto de pesquisa, pode exemplificar como a cultura e os valores da comunidade trazem identidade ao ambiente e como o design pode auxiliar na identificação da identidade local e reforçá-la, criando um senso de pertencimento e orgulho nos seus usuários.

$\mathrm{Na}$ contemporaneidade o design tem configuração diversa, com inúmeras possibilidades de relações e associações. É uma grande rede, um tecido entrelaçado e articulado, repleto de significações resultantes do entrelaçamento e articulação de signos que geram linguagens diferenciadas. Essa grande rede flexível atua na esfera da informação, comunicação e conhecimento, tem como foco central o homem, as dinâmicas e produções culturais que o envolvem. (MOURA, 2011, p. 89).

$O$ design vem construindo não só objetos e materiais para um uso objetivo e peremptório, mas ele vem embutido também de uma estrutura semiótica com uma carga subjetiva e abstrata. Assim, o modo como a sociedade se relaciona com esses objetos interferirá na cultura contemporânea provocando novos fenômenos comportamentais e gerando novas relações usuário-produto, produto-usuário.

Dessa forma, o design vê nas dinâmicas socioculturais um desafio para novas criações e evolução no que se diz respeito a criatividade e nas áreas técnicas de 
construção, como por exemplo, novos materiais a serem pensados e novas funções que se pode dar a um produto.

\subsection{Ações pensadas pelo design na Borrachalioteca}

O projeto inicial de pesquisa, desenvolvido pelo Grupo de Pesquisa Design e Representações Sociais da UEMG, financiado pelo CNPq, tinha como objetivo reformular o ambiente a partir de oficinas com os frequentadores, criar um espaço que fosse mais agradável e adequado aos usuários, a partir da utilização dos materiais ali presentes. No entanto, a partir de pesquisas bibliográficas, pesquisa de campo e questionários aplicados estabelecemos um maior entendimento das necessidades da Borrachalioteca.

A Borrachalioteca não tem imóveis próprios. O espaço físico é mantido por bolsas de fomento a cultura, que são vulneráveis, com prazos de início e término de financiamento.

Percebemos outras demandas, como por exemplo a participação em eventos fora da cidade de Sabará. Os jovens que participam de atividades na Borrachalioteca sempre estão viajando ou fazendo atividades fora do seu espaço, levando a leitura, a poesia, entre outras formas de arte e incentivando jovens e adultos à participação cultural. No entanto, o deslocamento de materiais para as atividades é sempre feito de maneira precária, assim como o palco para suas apresentações. A partir dessa demanda fomos instigados a pensar em soluções que pudessem auxiliar as apresentações em eventos da Borrachalioteca e que essa solução pudesse apresentar a biblioteca comunitária para as pessoas.

A "Borrachalioteca Sobre Rodas" (BSR) foi concebida para ser acoplada no veículo automotivo de forma simples e eficaz. O conceito da BSR é baseado na cultura cigana, inclusive na forma da carenagem, com o teto em semicírculo (abaulado). Seu desenho aponta como asas abertas nas laterais que insinuam o voo para 0 conhecimento através da leitura. Seu material em chapa de aço carbono e estrutura em metalon configuram-no como resistente a chuva e intempéries. Possui as prateleiras em de MDF com revestimento melamínico. As prateleiras irão transportar os livros da Borrachalioteca e no espaço interno onde podem ser transportados outros objetos como cadeiras e poofs para convidar as pessoas a se sentarem para ler um livro ou um cordel. O projeto é coordenado pela professora Rita A. C. Ribeiro, tem a autoria de Anderson Horta com o projeto gráfico da plotagem do designer Sérgio Luciano da Silva. Foi executado pela empresa Carretinhas Imperial.

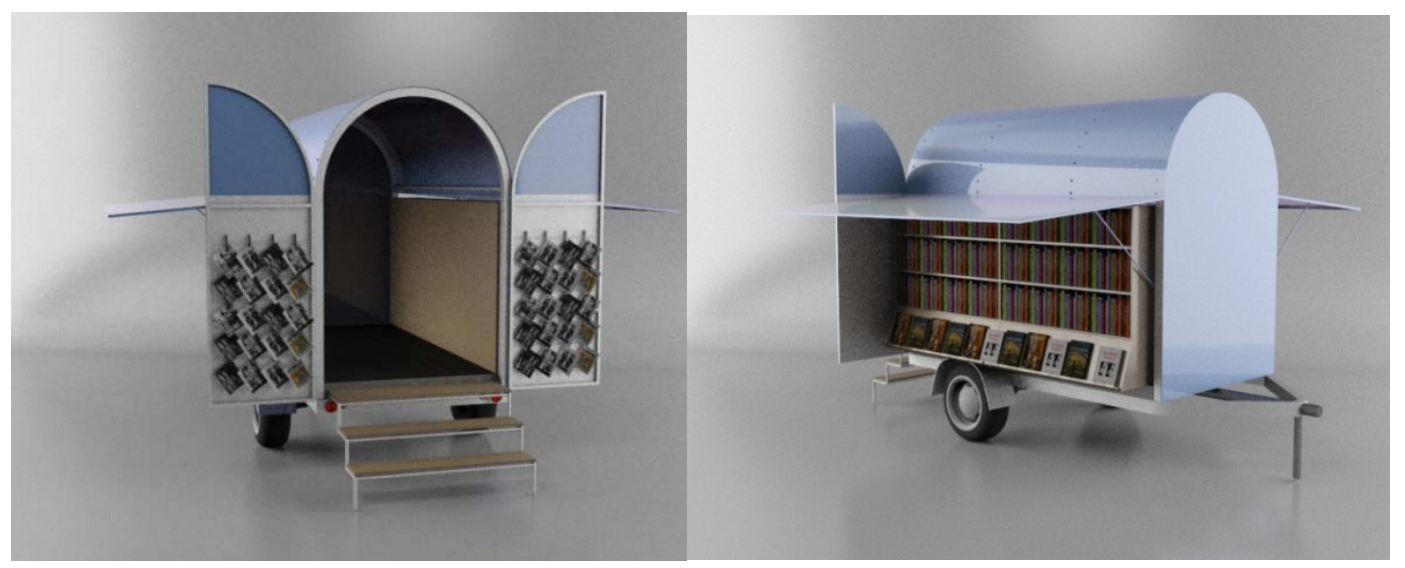

Figura 7: Borrachalioteca Sobre Rodas (protótipo).

Fonte: ANDERSON HORTA, 2015. 


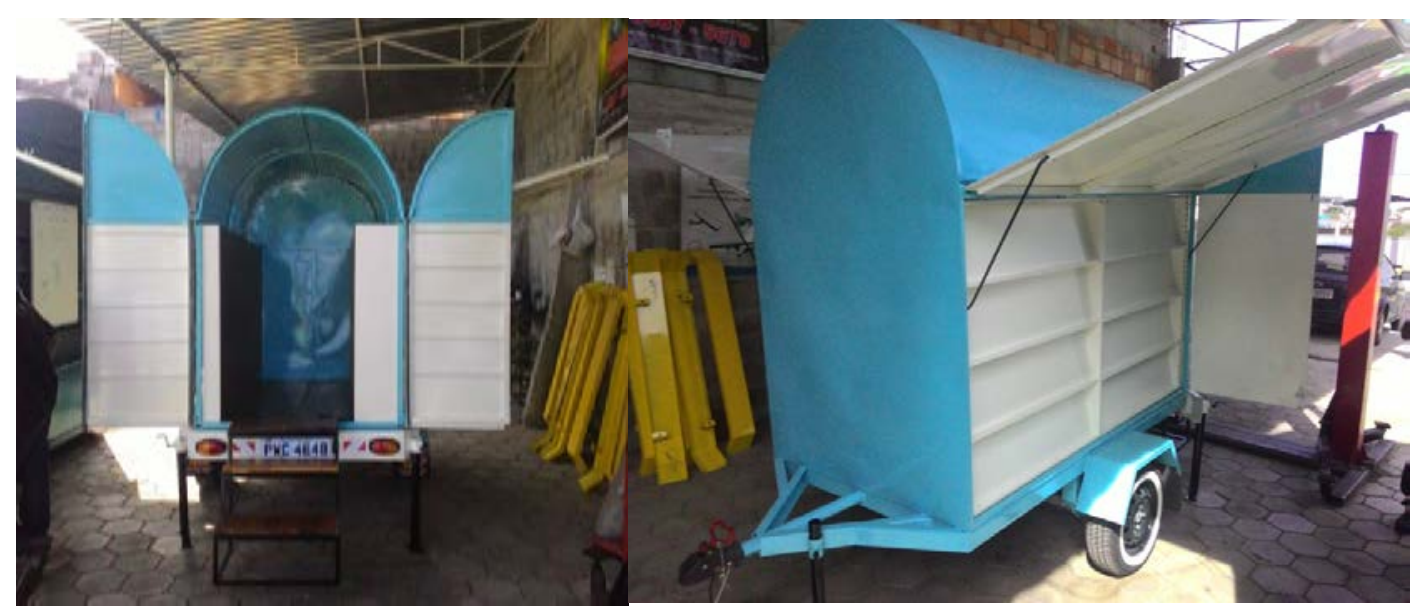

Figura 8: Borrachalioteca Sobre Rodas.

Fonte: ANDERSON HORTA, 2015.

\section{CONCLUSÃO}

O melhor ativo dos designers, atualmente, reside na sua percepção para ver a interconexão do mundo de um modo humanista. Nesse contexto, o Design se torna a linguagem dominante para promover a inovação. Pois cabe a ele o papel de viabilizar a natureza participativa dos profissionais, consumidores e da comunidade em geral, em torno de um novo conjunto de regras que privilegiam a usabilidade, mas pensando também nos fatores emocionais e na sustentabilidade. Assim, a função social do design transcende a forma e passa a pensar no projeto como parte de uma cadeia de valores sociais, que privilegia o humano.

A Borrachalioteca Sobre Rodas obteve êxito em sua inauguração nos dias 5 e 6 de dezembro de 2015 no Festival de Jabuticaba de Sabará. O evento contava com artesãos, produtores de jabuticabas, fabricantes de variedades de jabuticabas como geleias, doces caseiros, sabonetes, essências e perfumes, entre outras centenas de produtos. Além de tudo houve várias apresentações de cunho artístico e musical. 0 grupo da Borrachalioteca "Arautos da Poesia", se apresentou oferecendo poesias aos cidadãos e visitantes da cidade. A BSR teve o seu lugar no evento expondo os livros e convidando leitores e curiosos para se aproximarem. O resultado foi de plena interatividade entre os indivíduos e a BSR. Contando com pufes de pneu e outros assentos, crianças, jovens e adultos de todas as idades pegavam livros e se sentavam em algum lugar para ler.

A BSR conseguiu atingir a demanda na facilidade do transporte dos livros até o evento bem como a exposição e o convite para a comunidade. "O que temos aqui são pessoas que gostam de ler e se sentem a vontade com esse momento. Muita gente diz que brasileiro não gosta de ler e aqui vemos que isso não é verdade. Aqui está cheio de gente o dia todo." Diz Luciane, uma das organizadoras do projeto da Borrachalioteca. Dessa forma vê-se a necessidade de mais projetos e eventos que fomentem cada vez mais iniciativas como estas, que possam envolver toda a comunidade no intuito de valorização dos hábitos culturais, propiciando uma sociedade mais saudável, critica e engajada.

Desde o mês de dezembro de 2015 a BSR tem sido levada para várias comunidades periféricas da cidade de Sabará. A possibilidade de deslocamento dos livros e materiais proporciona momentos de leitura ao ar livre, com apresentações do 
grupo de poesia e doações de livros, levando os hábitos de leitura e promovendo entretenimento sociocultural a regiões distantes da sede física. Assim, com este projeto, acreditamos que o design pode e deve cruzar as fronteiras dos objetivos puramente comerciais, voltando-se para práticas de apoio social, como acontece com a BSR.

Por fim, agradecemos ao CNPq pelo apoio ao projeto tornando possível a conexão entre pesquisa e execução de um produto palpável que beneficia a melhoria da qualidade de pessoas, e motivando pesquisadores a continuarem investigando temas que tenham retorno sociocultural para a comunidade.

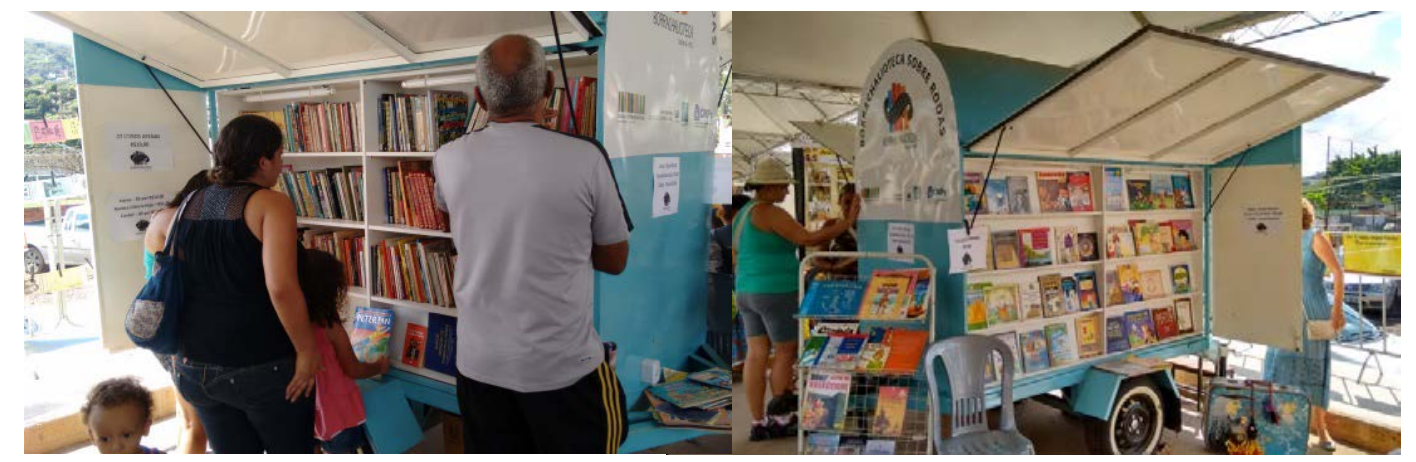

Figura 9: Visitantes procurando livros

Fonte: Elaborado pelo autor, com base na pesquisa realizada.

\section{REFERÊNCIAS}

COLL, Augustí Nicolau. Propostas para uma diversidade cultural intercultural na era da globalização. Coleção: Cadernos de proposições para o século XXI. São Paulo, Instituto Pólis, 2002. 124p.

FARIA, José Neto. MOURA, Mônica. Design e cultura contemporânea: a formação dos objetos culturais. São Paulo, 3, 14 p., maio de 2008. Disponível na internet por http em:http://wright.ava.ufsc.br/ alice/conahpa/anais/2008/conahpa2008.zip\%20Folder/ artigos/Design_e_cultura_contemporanea_a_formacao_dos_objetos_culturais.pdf

LARAIA, Roque de Barros. Cultura um conceito antropológico. Rio de Janeiro: Zahar, 1986. 108 p.

LÖBACH, Bernd. Design Industrial. Bases para a configuração dos produtos industriais. São Paulo: Edgard Blücher, 2001.

MELLO, Carolina luva de; PICHLER, Rosimeri Franck; MULLER, Caroline; ROMANO, Fabiane Vieira; BATTISTELLA, Luciana. Projeto Design Social: geração de renda e resgate cultural através do design associado ao artesanato. Disponível na internet por http em: http://revista.ibict.br/inclusao/index.php/inclusao/article/viewFile/229/213. Acesso em: 24 jan. 2104.

MORAES, Dijon. Design e multiculturalismo. In: MORAES, Dijon; (orgs.). Cadernos de estudos avançados em Design: multiculturalismo. 2a edição. Vol.1. Belo Horizonte: UEMG, 2013. 11-14 p..

MOURA, Mônica. Ensino e design no contemporâneo: dúvidas, desafios, expressões e discursos. In: Ensaios em Design: ensino e produção de conhecimento. Bauru, Canal 6, 2011. P.82-113. 
NOGUEIRA, José F. S. Etnodesign e cultura brasileira: memória, resgate e identidade. Universidade Católica Dom Bosco. Disponível na internet por http em:

file://C:/Users/clara\%20lins/Downloads/GT8-

\%20ETNODESIGN\%20E\%20CULTURA\%20BRASILEIRA\%20MEM\%C3\%93RIA,\%20RESGAT E\%20E\%20IDENTIDADE.pdf. Acesso em: 10 ago. 2014

Biblioteca amigos da Leitura. Disponível na internet por http em:

http://www.bibliotecaamigosdaleitura.com.br/. Acesso em: 29 de jun., 2015.

Borrachalioteca. Disponível na internet por http em:

http://borrachalioteca.blogspot.com.br/. Acesso em: 10 ago. 2014.

Design Coletivo. Disponível na internet por http em:

http://www.designcoletivo.com/conceitos/design-social/. Acesso em: 29 jun. 2015.

Ecofuturo. http://blog.ecofuturo.org.br/categoria/promocao-de-leitura. Acesso em: 29 jun. 2015.

Hipporoller. Disponível na internet por http em: http://hipporoller.org/social-impact. Acesso em: 29 jun. 2015. 